Bentham OPEN
CrossMark
Content list available at: www.benthamopen.com/TODENTJ/

RESEARCH ARTICLE

\title{
Expression of Vascular Endothelial Growth Factor in Odontogenic Cysts: Is There Any Impression on Clinical Outcome?
}

\author{
Donia Sadri, Sareh Farhadi ${ }^{*}$ Zahra Shahabi and Samaneh Sarshar \\ Department of Oral and Maxillofacial Pathology, Dental Branch of Tehran, Islamic Azad University, Tehran, Iran
}

Received: July 25, 2016

Revised: November 06, 2016

Accepted: December 08, 2016

\section{Abstract:}

Background:

The recent scientific reports have shown that angiogenesis can affect biological behavior of pathologic lesions.

\section{Objective:}

Regarding unique clinical outcome of Odontogenic keratocyst (OKC), the present study was aimed to compare angiogenesis in Odontogenic keratocyst and Dentigerous cyst (DC).

\section{Method:}

In this experimental study, tissue sections of 46 samples of OKC and DC were stained through immunohistochemical method using Vascular Endothelial Growth Factor (VEGF) antibody. VEGF expression was evaluated in epithelial cells, fibroblasts and endothelial cells. The average percentage of stained cells in any samples was categorized to 3 groups as follows: SCORE 0: 10\% of cells or less are positive. SCORE 1: 10 to $50 \%$ of cells are positive. SCORE 2: more than 50\% of cells are positive. Mann-U-Whitney, T-test and chi-square was used for statistical analysis.

\section{Result:}

The average of VEGF expression in 24 samples of DC was $20.2 \%$ and in 22 samples of OKC was $52.6 \%$, respectively. The average of VEGF expression in these two cysts had statistical significant differences. ( $\mathrm{PV}=0.045)$. There was significant statistical differences between two cysts in the terms of VEGF SCORE $(\mathrm{PV}=0.000)$. OKC samples had significantly higher SCORE for the purpose of VEGF incidence than DC. Also, there were no differences between VEGF expression in epithelial cells of two cysts (PV= 0.268) there were significant statistical differences between two cysts in terms of endothelial cell staining. The endothelial cell staining was significantly higher in OKC than DC $(\mathrm{PV}=0.037 \%)$.

\section{Conclusion:}

Regarding higher expression of Vascular Endothelial Growth factor in OKC than DC, it seems that angiogenesis may have great impression on clinical outcome of OKC.

Keywords: Angiogenesis, Dentigerous cyst, Immunohistochemical, Odontogenic cyst, Odontogenic keratocyst, VEGF.

\section{INTRODUCTION}

Cysts are the most common destructive oral and maxillofacial lesions [1]. Dentigerous cyst (DC) is the most common developmental odontogenic cyst which has good prognosis and low recurrence rate and forms $20 \%$ of oral cysts [2]. Typically, patients with odontogenic cysts are asymptomatic and the lesions are discovered on radiographic

\footnotetext{
* Address correspondence to this author at the Department of Oral and Maxillofacial Pathology, Dental Branch of Tehran, Islamic Azad University, $177,5^{\text {th }}$ Golestan St., Pasdaran St., Tehran, Iran; Tel: +98 21 22542238; E-mail: dr.sfarhadi@gmail.com
} 
examinations or when films are taken to find out the reason for failure of a tooth to erupt. Unfrequently, a dentigerous cyst may grow to a significant size and result in cortical expansion of the bone and facial asymmetry, and very rarely predisposes the patient to a pathologic fracture $[3,4]$.

Furthermore, Odontogenic keratocyst $(\mathrm{OKC})$ is famous regarding its unique histopathological features, high recurrence rate and aggressive biological behavior. In addition to a distinctive biological behavior, the expression of various proliferation markers in the cyst wall and mutation in p53 and PTCH gene, have led several investigators to consider KOT as a benign cystic neoplasm [5 - 7].

Odontogenesis is controlled by interaction between the epithelial and mesenchymal components of developing dental tissues regarding the fact that odontogenic cysts and tumors arise from tissue remains of odontogenesis, these interactions have been considered to play an important role in tumorogenesis of odontogenic lesions. The connective tissue stroma has an essential role in proliferation of epithelium even the minor alteration of epitelium is followed by corresponding changes in the stroma such as angiogenesis [8].

Vascular Endothelial Growth Factor (VEGF) is a multifunctional cytokine that expresses in different situations and has a role in increasing the vascular permeability and angiogenesis, stimulating the endothelial cells proliferation and migration [8]. So it can increase the permeability of small vessels density 5000 units more than Histamines [9]. This cytokine is produced by different kinds of cells and operates as a main regulator of physiologic and pathologic angiogenesis $[10,11]$.

Angiogenesis has been evaluated in various pathologic lesions including breast cancer, melanoma, ameloblastoma and etc. using different angiogenic markers [12 - 15], but the number of studies focusing on angiogenesis in odontogenic cysts is limited. So, regarding different clinical behavior of oral and maxillofacial cysts and lack of information regarding concerned biologic factors and also the importance of early diagnosis and treatment to prevent or at least reduce the risk of recurrence and malignancy changes, further studies were recommended.

The last reports have shown that vascular density of the lesions affects their biological behavior [16]. So, new treatments are based on reduction of the vascular density [17]. According to the importance of this subject and lack of information about it, the present study was aimed to compare the VEGF expression in OKC and DC samples referred to the Oral \& Maxillofacial pathology department, Dental branch of Tehran, Islamic Azad University during 2006 to 2014.

\section{METHODS AND MATERIALS}

In this experimental study, the paraffin blocks of 46 samples including 22 cases of OKC and 24 cases of DC, were sectioned for Hematoxilin-Eosin staining. After observing the H\&E slides by two pathologists, the samples with sufficient tissue and appropriate fixation were selected. Also, the samples with necrotic tissue or bleeding or excessive swelling and insufficient tissue and related to recurrence of odontogenic lesions were excluded from the study.

Immunohistochemical staining was performed on the $5 \mu$ paraffin sections over the Poly-1-lysin-coated glass slides. After heat drying, they were deparaffinazed in Xylene and rehydrated in Ethanol with TUF in $90^{\circ} \mathrm{C}$ for 10 minutes to remove antigen's cover. After 3 times rinsing with $4^{\circ} \mathrm{C}$ water they were incubated by $1 / 200$ diluted monoclonal antibody VEGF-VGI made by (DAKO, Denmark). Finally, that slides were incubated by Streptevidin-BiotinPeroxidase method with diaminobanzidin 3.3 and were stained by Hematoxilin. In this staining procedure, placental tissues were considered as a positive control [18].

The evaluation of VEGF expression was performed by Rubini et al. method [18]. In summary the VEGF incidence with counting the stained cells includes epithelial cells, fibroblasts and endothelial cells in 5 microscopic fields. The average of positive cell's percentage in each sample was reported and was categorized as follows:

SCORE $0: 10 \%$ of cells or less have showed the VEGF staining.

SCORE 1: 10 to $50 \%$ of cells have showed the VEGF staining.

SCORE 2: more than $50 \%$ of cells have showed the VEGF staining.

Optical microscope NIKON (Japan) with 400\% magnification was used. Fig. (1) shows the expression of VEGF in OKC sample with epithelial, endothelial and fibroblast expression by $\mathrm{x} 200$ magnification. 


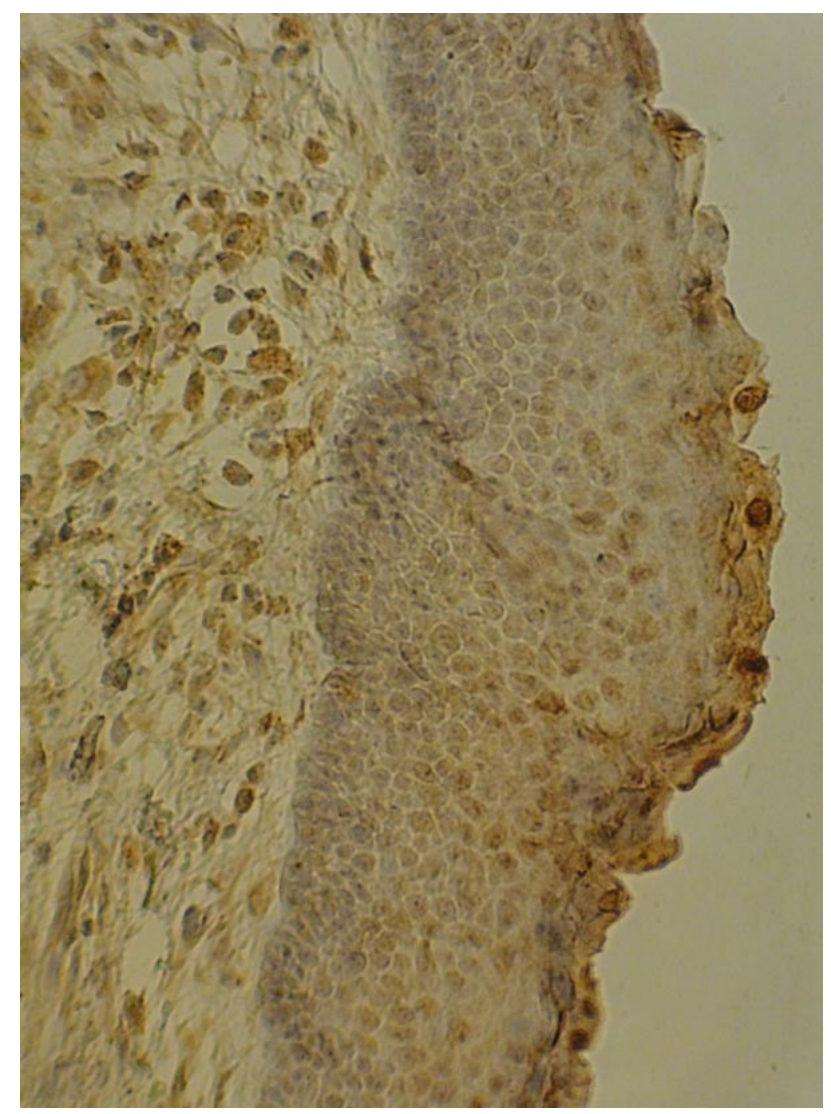

Fig. (1). Expression of VEGF in OKC sample by x200 magnification.

Also, Fig. (2) demonstrates the expression of VEGF in DC sample with epithelial, endothelial and fibroblast expression by $\mathrm{x} 200$ magnification.

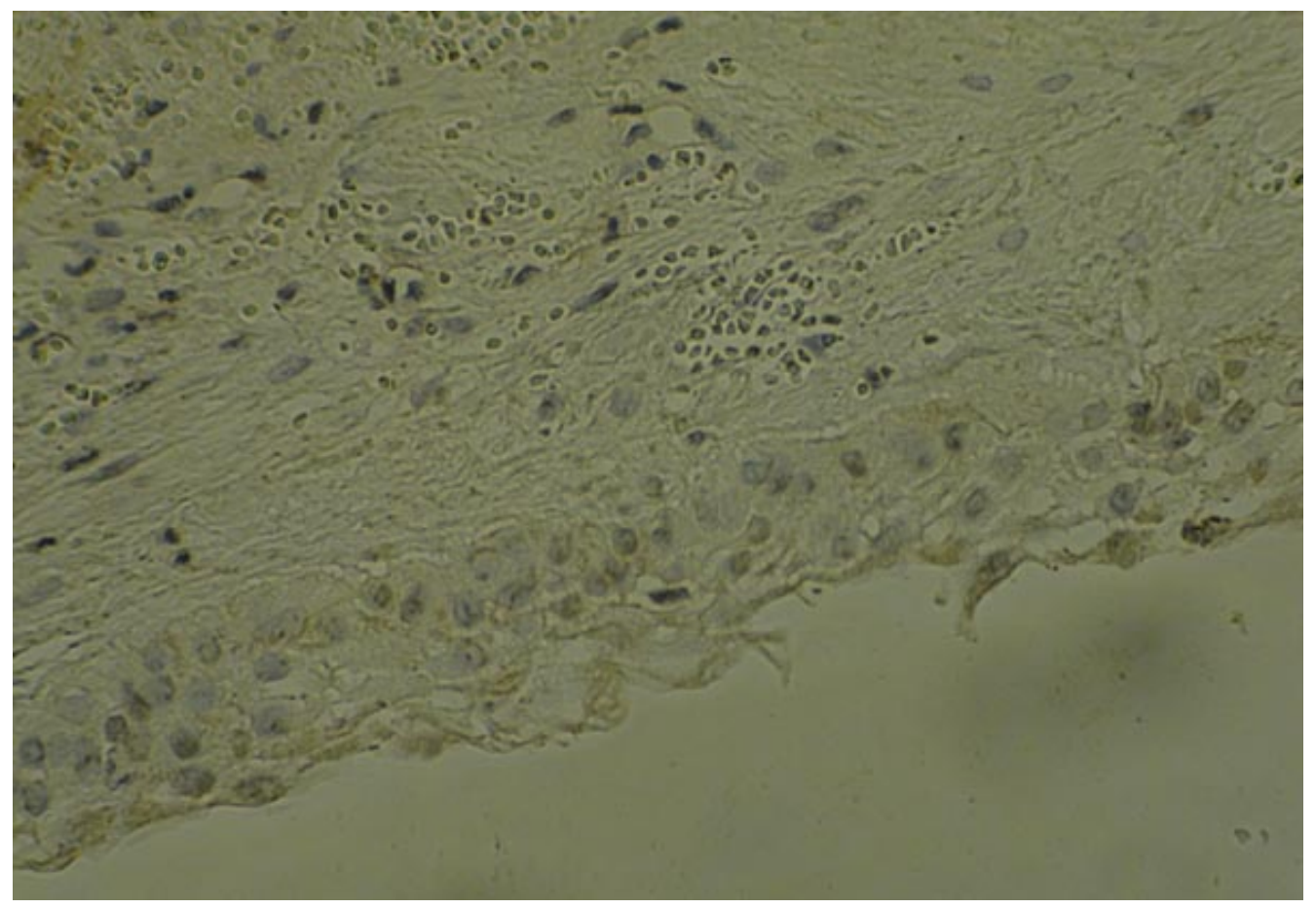

Fig. (2). Expression of VEGF in DC sample by x200 magnification. 
Finally, for statistical analysis the Mann-U-Whitney, T-test and chi-square was used and the significance level was considered lower than 0.05 .

\section{RESULTS}

The results of study on 46 samples including 22 cases of OKC and 24 cases of DC are shown in Tables 1 to 4 .

Table 1. Comparison of VEGF expression percentage in OKC and DC.

\begin{tabular}{|c|c|c|c|c|c|c|}
\hline \multicolumn{2}{|c|}{ Lesion } & N & Minimum & Maximum & Mean & SD \\
\hline DC & VEGF & 24 & 4 & 40.2 & 20.2 & 11.86 \\
\hline OKC & VEGF & 22 & 14 & 79 & 52.6 & 19.98 \\
\hline
\end{tabular}

Table 1 shows that the least percent of VEGF in DC was $40 \%$ and the most was $40.2 \%$ and also the average percent of VEGF in this cyst was $20.2 \%$ and the related standard deviation was $11.86 \%$.

Also the least percent of VEGF in OKC was $14 \%$ and the most was $79 \%$ and the average of VEGF percentage in this cyst was $52.6 \%$ with standard deviation of $19.98 \%$.

\section{Comparison of VEGF Expression Percentage in DC and OKC}

The expression of VEGF in this two cysts has significant statistical differences with significantly higher expression of VEGF in odontogenic keratocyst than dentigerous cyst $(\mathrm{PV}=0.045)$.

\section{Comparison of VEGF Expression Based on VEGF Score}

Table 2 shows in 10 samples of DC SCORE 0 was reported 41.7\% and in 14 samples of this cyst SCORE 1 was reported 58.3\%. Also in 6 samples of OKC SCORE 1 was $27.3 \%$ and in 16 samples SCORE 2 was $72.7 \%$ and SCORE 0 was not reported in any sample.

Table 2. Comparison of vascular density base on VEGF SCORE in OKC and DC.

\begin{tabular}{|c|c|c|c|c|c|}
\hline \multicolumn{2}{|c|}{ Samples } & \multicolumn{2}{|c|}{ VEGF score } & \multirow{2}{*}{ Total } \\
\cline { 3 - 6 } \multicolumn{2}{|c|}{} & 0 & $\mathbf{1}$ & $\mathbf{2}$ & 24 \\
\hline & DC(count) & $\mathbf{1 0}(41.7 \%)$ & $\mathbf{1 4}(58.3 \%)$ & $\mathbf{1 6}(72.0 \%)$ & 22 \\
\cline { 2 - 5 } & OKC(count) & $\mathbf{0}(0.0 \%)$ & $\mathbf{6}(27.3 \%)$ & $\mathbf{1 6}(34.8 \%)$ & 46 \\
\hline
\end{tabular}

There was significant statistical differences between two cysts in the terms of VEGF score $(P V=0.000)$. It means OKC samples had significantly higher VEGF score than DC.

In the next step, the relationship between VEGF expressions was evaluated in different cells regardless of the lesion.

According to Table 3, 5 cases of DC (20.8\%) and 2 cases $(9.1 \%)$ of OKC $(79.2 \%)$ were not expressed VEGF by epithelial cell. 19 cases (79.2\%) of DC and 20 cases(90.9\%) of OKC cases had epithelial VEGF expression . There were no significant differences between VEGF expression in epithelial cells of two cysts $(\mathrm{PV}=0.268)$.

Table 3. Comparison of VEGF expression in epithelial cells of OKC and DC.

\begin{tabular}{|c|c|c|c|c|}
\hline \multicolumn{2}{|c|}{ Samples } & \multicolumn{2}{|c|}{ Epithelial cells } & \multirow{2}{*}{ Total } \\
\cline { 3 - 5 } \multicolumn{2}{|c|}{} & NO & YES & \\
\hline \multirow{2}{*}{ DC(count) } & $5(20.8 \%)$ & $20(79.2 \%)$ & 24 \\
\cline { 2 - 5 } & OKC(count) & $2(9.1 \%)$ & $39(84.8 \%)$ & 22 \\
\hline
\end{tabular}

According to Table 4, 15 cases of DC samples (62.5\%) had no endothelial cell VEGF expression but 9 cases (37.5\%) expressed it. Also 7 cases (31.8\%) of OKC had no endothelial cell VEGF expression but 15 cases (68.2\%) expressed it. There were significant statistical differences between two cysts in the terms of endothelial cell VEGF expression. It means that the endothelial cell expression was significantly higher in OKC than DC $(\mathrm{PV}=0.037)$. 
Table 4. Comparison of VEGF expression in endothelial cells of OKC and DC.

\begin{tabular}{|c|c|c|c|c|}
\hline \multicolumn{2}{|c|}{ Samples } & \multicolumn{2}{c|}{ Total } \\
\cline { 3 - 5 } \multicolumn{2}{|c|}{ NO } & \multicolumn{2}{c|}{ YES } & \\
\hline \multirow{2}{*}{} & DC(count) & $15(62.5 \%)$ & $9(37.5 \%)$ & 24 \\
\cline { 2 - 5 } & OKC(count) & $7(31.8 \%)$ & $15(68.2 \%)$ & 22 \\
\hline Total & $22(47.8 \%)$ & $24(52.2 \%)$ & 46 \\
\hline
\end{tabular}

The statistical analysis about fibroblasts was not evaluated because $100 \%$ of cells in both cysts were stained.

\section{DISCUSSION}

Our results have shown that the percentage of VEGF expression in OKC is significantly higher than DC (PV= 0.045). Also OKC samples had significantly higher VEGF score than DC $(P V=0.000)$. In addition, there were no differences between VEGF expressions in epithelial cells of two cysts but there were significant statistical differences between two cysts in the terms of endothelial cell staining which means that the endothelial cell staining was significantly higher in $\mathrm{OKC}$ than $\mathrm{DC}(\mathrm{PV}=0.037)$.

In the study by Rubini et al. [18] and also Mitrou GK et al. [19], similar to our results indicated that the expression of VEGF in OKC is more over DC. On the other hand, Nonaka C et al. [20] have shown that VEGF expression had significant relation with vascular density and angiogenesis marker.

The higher angiogenesis and vascular density and severity of inflammation increase were reported to higher expression of VEGF, too [20]. Similarly, Leonardi R et al. had reported the incidence of VEGF in periapical granuloma and radicular cyst and have related the rate of incidence with the pattern of placement of inflammatory cells [21].

The expression of VEGF was reported in many pathologic lesions so far, for example some researchers have related the incidence of VEGF with poor prognosis of breast cancer. Moreover, so many studies have shown that overall survival and disease-free survival in those tumors have decreased with increasing the VEGF expression. Also the increase of VEGF can be the first step of metastatic process that includes changes in angiogenesis. Although the VEGF is related to poor survival but its exact mechanism of action in developing tumors, is still unknown [22]. Of course it has been shown when VEGF releases, it might stimulate many responses and in this way it might cause the cell's survival, movement or differentiation. Therefore, the VEGF is the potential target for the treatment of cancers [23].

Also, there were studies around VEGF expression in other pathologic lesions except tumors which had reported that the angiogenesis and related factors are necessary for growing pathologic lesions [24, 25]. These studies have found that when VEGF signals are inhibited, the angiogenesis and as a result, growth of pathologic lesions stops [26, 27] VEGF also has a role in formation of pathologic lesions by inducing permeability of blood vessels that facilitates the extravasation phenomenon and leads to create a matrix to support the growth of endothelial and tumoral cells. Thereby, it allows the pathologic lesions to grow in adjacent tissue $[28,29]$.

There are a few studies in the case of VEGF expression in cysts and especially odontogenic cysts in which they have reported the increase of VEGF in OKC. The results of present study have confirmed the last subject in line with previous studies, thus according to the describing mechanism of VEGF function [30 - 32], it seems that angiogenesis can have a significant impact on the clinical outcome of OKC. This means according to stimulator role of VEGF in endothelial cell's formation, proliferation and migration, it can cause an increase in vascular density and thus more aggressive behavior of OKC than DC [33]. Also because the VEGF is progenitor rather than other vascular markers and has expression in epithelial cells and fibroblasts in addition to endothelial cells and can cause the induction of vascular density that leads to increasing extravasation of plasma proteins and finally fluid aggregation, it seems that VEGF incidence in cystic lesions has specific effect on the fluid aggregation in the cysts and its excessive growth [20]. On the other hand, according to the present study resulting to higher VEGF expression in endothelial cells of OKC than DC, in addition to fluid aggregation, VEGF can be effective on excessive growth of cysts by the induction of angiogenesis in their stroma.

Therefore, it seems that angiogenesis may associate with different biological behaviors of these lesions and at least to some degree can reflect their clinical features. The clinical significance of the present results may be helpful to the surgical procedures of these lesions even the post operation bone healing and using the graft for grater lesions [34]. However, the results of present study can be a small step in the discovery of unknowns in this scientific field. In the present study, due to limitation of case numbers and absence of follow up information, complete evaluation of the issue 
was impossible. So, it is recommended to schedule future studies evaluating the angiogenesis between aggressive and nonaggressive case of both lesions and also preparing the follow up evaluation of cases leading to better understanding of the clinical impression of recent findings.

\section{CONCLUSION}

In the present study, angiogenesis by VEGF expression was significantly higher in OKC than DC. Also this difference was higher in endothelial cells rather than epithelial cells and fibroblasts. So, it seems angiogenesis that may have great impression on clinical outcome of OKC.

\section{LIST OF ABBREVIATIONS}

$\begin{array}{lll}\text { DC } & = & \text { Dentigerous Cyst } \\ \text { OKC } & = & \text { Odontogenic Keratocyst } \\ \text { VEGF } & = & \text { Vascular Endothelial Growth Factor }\end{array}$

\section{CONFLICT OF INTEREST}

The authors confirm that this article content has no conflict of interest.

\section{ACKNOWLEDGEMENTS}

We appreciate technical support of Rasht Razi Lab., Dr. Fatemeh Shahsavari and also we thank to Dr. Mohammad Javad Kharazifard for preparation of statistical analysis.

\section{REFERENCES}

[1] Patidar KA, Parwani RN, Wanjari SP, Patidar AP. Mast cells in human odontogenic cysts. Biotech Histochem 2012; 87(6): 397-402. [http://dx.doi.org/10.3109/10520295.2012.674556] [PMID: 22574881]

[2] Neville B, Damm D, Allen C. Oral \& Maxillofacial Pathology. $3^{\text {rd }}$ ed. Philadelphia: WB Saunders co. 2009; pp. 678-701.

[3] Regezi JA, Sciubba JJ, Jordan RC. Oral pathology: clinical pathologic correlations. $6^{\text {th }}$ ed. St Louis: Saunders Elsevier 2011 ; pp. $237-51$.

[4] Akyol UK, Salman IA. A case of an extensive dentigerous cyst in the maxillary sinus leading to epiphora and nasal obstruction. J Emerg Med 2012; 43(6): 1004-7.

[http://dx.doi.org/10.1016/j.jemermed.2010.11.045] [PMID: 21310578]

[5] Shear M. The aggressive nature of the odontogenic keratocyst: is it a benign cystic neoplasm? Part 1 . Clinical and early experimental evidence of aggressive behaviour. Oral Oncol 2002; 38(3): 219-26. [http://dx.doi.org/10.1016/S1368-8375(01)00065-3] [PMID: 11978543]

[6] Thosaporn W, Iamaroon A, Pongsiriwet S, Ng KH. A comparative study of epithelial cell proliferation between the odontogenic keratocyst, orthokeratinized odontogenic cyst, dentigerous cyst, and ameloblastoma. Oral Dis 2004; 10(1): 22-6. [http://dx.doi.org/10.1046/j.1354-523X.2003.00974.x] [PMID: 14996290]

[7] Tsuneki M, Cheng J, Maruyama S, Ida-Yonemochi H, Nakajima M, Saku T. Perlecan-rich epithelial linings as a background of proliferative potentials of keratocystic odontogenic tumor. J Oral Pathol Med 2008; 37(5): 287-93. [http://dx.doi.org/10.1111/j.1600-0714.2007.00620.x] [PMID: 18205742]

[8] Puthiyaveetil JS, Kota K, Chakkarayan R, Chakkarayan J, Thodiyil AK. Epithelial - mesenchymal interactions in tooth development and the significant role of growth factors and genes with emphasis on mesenchyme - a review. J Clin Diagn Res 2016; 10(9): ZE05-9. [PMID: 27790596]

[9] Folkman J. Angiogenesis in cancer, vascular, rheumatoid and other disease. Nat Med 1995; 1(1): $27-31$. [http://dx.doi.org/10.1038/nm0195-27] [PMID: 7584949]

[10] Brown LF, Detmar M, Claffey K, et al. Vascular permeability factor/vascular endothelial growth factor: a multifunctional angiogenic cytokine. EXS 1997; 79: 233-69.

[http://dx.doi.org/10.1007/978-3-0348-9006-9_10] [PMID: 9002222]

[11] Ferrara N, Davis-Smyth T. The biology of vascular endothelial growth factor. Endocr Rev 1997; $18(1)$ : 4-25. [http://dx.doi.org/10.1210/edrv.18.1.0287] [PMID: 9034784]

[12] Maruthanila VL, Elancheran R, Kunnumakkara AB, Kabilan S, Kotoky J. Recent development of targeted approaches for the treatment of breast cancer. Breast Cancer 2016. [Epub ahead of print] [http://dx.doi.org/10.1007/s12282-016-0732-1] [PMID: 27796923]

[13] Gaustad JV, Simonsen TG, Andersen LM, Rofstad EK. Properdistatin inhibits angiogenesis and improves vascular function in human 
melanoma xenografts with low thrombospondin-1 expression. Oncotarget 2016. [Epub ahead of print] [http://dx.doi.org/10.18632/oncotarget.12695] [PMID: 27756886]

[14] Shahsavari F, Farhadi S, Sadri D, Sedehi M. Evaluation of microvascularity by CD34 expression in esophagus and oral squamous cell carcinoma. J Contemp Dent Pract 2015; 16(6): 458-62. [http://dx.doi.org/10.5005/jp-journals-10024-1706] [PMID: 26323448]

[15] Alaeddini M, Salah S, Dehghan F, Eshghyar N, Etemad-Moghadam S. Comparison of angiogenesis in keratocystic odontogenic tumours, dentigerous cysts and ameloblastomas. Oral Dis 2009; 15(6): 422-7. [http://dx.doi.org/10.1111/j.1601-0825.2009.01566.x] [PMID: 19413675]

[16] Sargolzaei S, Farhadi S, Kazemi B, Bandehpour M, Kharazifard MJ. The correlation between p16 expression and INK4a locus mutation with grades and stages in oral squamous cell carcinoma. Indian J Pathol Microbiol 2014; 57(1): 24-30. [http://dx.doi.org/10.4103/0377-4929.130877]

[17] Seifi S, Shafaie S, Ghadiri S. Microvessel density in follicular cysts, keratocystic odontogenic tumours and ameloblastomas. Asian Pac J Cancer Prev 2011; 12(2): 351-6. [PMID: 21545193]

[18] Rubini C, Artese L, Zizzi A, et al. Immunohistochemical expression of vascular endothelial growth factor (VEGF) in different types of odontogenic cysts. Clin Oral Investig 2011; 15(5): 757-61. [http://dx.doi.org/10.1007/s00784-010-0433-7] [PMID: 20563616]

[19] Mitrou GK. Odontogenic keratocyst expression vascular endothelial growth factor an immunohistochemical study. Oral pathol Med 2009; 38(5): 470-5.

[20] Nonaka CF, Maia AP, Nascimento GJ, de Almeida Freitas R, Batista de Souza L, Galvão HC. Immunoexpression of vascular endothelial growth factor in periapical granulomas, radicular cysts, and residual radicular cysts. Oral Surg Oral Med Oral Pathol Oral Radiol Endod 2008; 106(6): 896-902. [http://dx.doi.org/10.1016/j.tripleo.2008.06.028] [PMID: 18755620]

[21] Leonardi R, Caltabiano M, Pagano M, Pezzuto V, Loreto C, Palestro G. Detection of vascular endothelial growth factor/ vascular permeability factor in periapical lesions. J Endod 2003; 29(3): 180-3. [http://dx.doi.org/10.1097/00004770-200303000-00004] [PMID: 12669876]

[22] Amo Y, Masuzawa M, Hamada Y, Katsuoka K. Serum concentrations of vascular endothelial growth factor-D in angiosarcoma patients. Br J Dermatol 2004; 150(1): 160-1. [http://dx.doi.org/10.1111/j.1365-2133.2004.05751.x] [PMID: 14746640]

[23] Liu E, Morimoto M, Kitajima S, et al. Increased expression of vascular endothelial growth factor in kidney leads to progressive impairment of glomerular functions. J Am Soc Nephrol 2007; 18(7): 2094-104. [http://dx.doi.org/10.1681/ASN.2006010075] [PMID: 17554151]

[24] Farhadi S, Shahsavari F, Taleghani F, Komasi E. Mast cell concentrations in peripheral and central giant cell granulomas: is there any angiogenetic role? Asian Pac J Cancer Prev 2016; 17(2): 673-6. [http://dx.doi.org/10.7314/APJCP.2016.17.2.673] [PMID: 26925662]

[25] Ferrara N, Chen H, Davis-Smyth T, et al. Vascular endothelial growth factor is essential for corpus luteum angiogenesis. Nat Med 1998; 4(3): 336-40. [http://dx.doi.org/10.1038/nm0398-336] [PMID: 9500609]

[26] Kumamoto H, Ohki K, Ooya K. Association between vascular endothelial growth factor (VEGF) expression and tumor angiogenesis in ameloblastomas. J Oral Pathol Med 2002; 31(1): 28-34. [http://dx.doi.org/10.1046/j.0904-2512.2001.10061.x] [PMID: 11896820]

[27] Dvorak AM, Kohn S, Morgan ES, Fox P, Nagy JA, Dvorak HF. The vesiculo-vacuolar organelle (VVO): a distinct endothelial cell structure that provides a transcellular pathway for macromolecular extravasation. J Leukoc Biol 1996; 59(1): 100-15. [PMID: 8558058]

[28] Dvorak HF, Nagy JA, Berse B, et al. Vascular permeability factor, fibrin, and the pathogenesis of tumor stroma formation. Ann N Y Acad Sci 1992; 667: 101-11. [http://dx.doi.org/10.1111/j.1749-6632.1992.tb51603.x] [PMID: 1309029]

[29] Claesson-Welsh L. VEGF-B taken to our hearts: specific effect of VEGF-B in myocardial ischemia. Arterioscler Thromb Vasc Biol 2008; 28(9): 1575-6 [http://dx.doi.org/10.1161/ATVBAHA.108.170878] [PMID: 18716319]

[30] Holmes K, Roberts OL, Thomas AM, Cross MJ. Vascular endothelial growth factor receptor-2: structure, function, intracellular signalling and therapeutic inhibition. Cell Signal 2007; 19(10): 2003-12. [http://dx.doi.org/10.1016/j.cellsig.2007.05.013] [PMID: 17658244]

[31] Karkkainen MJ, Petrova TV. Vascular endothelial growth factor receptors in the regulation of angiogenesis and lymphangiogenesis. Oncogene 2000; 19(49): 5598-605. [http://dx.doi.org/10.1038/sj.onc.1203855] [PMID: 11114740]

[32] Oltmanns KM, Gehring H, Rudolf S, et al. Acute hypoxia decreases plasma VEGF concentration in healthy humans. Am J Physiol Endocrinol Metab 2006; 290(3): E434-9. 
[http://dx.doi.org/10.1152/ajpendo.00508.2004] [PMID: 16219663]

[33] de Moraes M, de Matos FR, de Souza LB, de Almeida Freitas R, de Lisboa Lopes Costa A. Immunoexpression of RANK, RANKL, OPG, VEGF, and vWF in radicular and dentigerous cysts. J Oral Pathol Med 2013; 42(6): 468-73. [http://dx.doi.org/10.1111/jop.12036] [PMID: 23278112]

[34] Laino L, Troiano G, Lo Muzio L, Menditti D, Herford AS, Cicciù M. Bone healing in the surgical treatment of dentigerous cysts in critically Ill patients. J Craniofac Surg 2015; 26(6): 2030-1.

[http://dx.doi.org/10.1097/SCS.0000000000001947] [PMID: 26267567]

(c) Sadri et al.; Licensee Bentham Open

This is an open access article licensed under the terms of the Creative Commons Attribution-Non-Commercial 4.0 International Public License (CC BY-NC 4.0) (https://creativecommons.org/licenses/by-nc/4.0/legalcode), which permits unrestricted, non-commercial use, distribution and reproduction in any medium, provided the work is properly cited. 